\title{
Multiagent Modeling and Simulation in Human-Robot Mission Operations Work System Design
}

\author{
Maarten Sierhuis', William J. Clancey', Michael H. Sims \\ Computational Sclences Division \\ N.ASAidmes Research Center \\ Moffett Field. CA 94035 \\ ímsierhuis, bclancey msimsi@amail.urc.nasa.gov
}

\begin{abstract}
This paper describes a collaborative multiagent modeling and simulation approach for designing work systems. The Brahms environment is used to model mission operations for a semi-autonomous robot mission to the Moon at the work practice level. It shows the impact of human-decision making on the activities and energy consumption of a robot.

A collaborative work systems design methodology is described that allows informal models, created with users and stakeholders, to be used as input to the development of formal computational models.
\end{abstract}

\section{Introduction}

Work systems involve people, machines, tools, documents, and facilities interacting in activities over time. These activities produce goods, services or-as is the case in the work system described in this paperscientific data. Many work systems we encounter everyday have existed over a long period of time. Improvement of such work systems is often done through business process analysis and reengineering [1]. But managers must also design work systems de novo.

One of the challenges of work system design is that work systems are often large and complex and persist over a long period of time. This makes the design process complex and non-deterministic. In this paper we describe Brahms, a multiagent modeling and simulation (M\&S) environment for designing complex interactions in human-machine systems.

In Brahms, we model work processes at the work practice level. We describe a case study in which we used Brahms to design mission operations for a proposed discovery mission to the Moon-the Victoria Mission. We begin by describing our view of work practice and how it is modeled in Brahms. We then describe Victoria, the model, and simulation results.

\section{Work Practice}

The concept of work practice originates in the research disciplines of socio-technical systems, business anthropology, and management science. Work systems design. as presented here, has its roots in the design of socio-technical systems. This method was developed in the $1950 \mathrm{~s}$ by Eric Trist and Fred Emery [2], to understand and leverage the advantages of the social and technical aspects of work. Work systems design extends this tradition by focusing on both the informal and formal fearures of work by applying ethnographic participant observation [3].

A work practice is defined as the collecrive activities of a group of people who collaborate and communicate, while performing these activities synchronously or asynchronously. In contrast, a Tayloristic view of work abstracts circumstances, tools, and behaviors into an idealized transformation of work products by job functions.

To describe how work actually gets done. we need to include those aspects of the situation that influence individual activity (not only the procedures and problem-solving behavior), such as collaboration, conversations, "off-task" activities, mult1-tasking, intertuption and resumption of work (and how this is managed), informal interaction such as assistance outside of job tunction, use of tools. and lacilities [4]

\footnotetext{
' Ruscarch Instutute of Ndvanced Computer Sitence (RLACSUSRA).

: Institute tor Human and Machinc Cognition (University of West Flonda, Pensacola)
} 
Brahms is a W\&S environment for representing work pracke usmg a muleagent rule-based acturly language. that win he imulated using the Brahms simulation engine [5]

This paper discusses how we have used Brahms to design the work system for the proposed Victoria inission. The attentive reader might question how we can design a work practice? Indeed. a work practice is not designed. but emerges over time. However, our interest is to detcrmine wherher a model at the work practice level can be used in the design of a mission. We believe that a work practice model is useful, because it provides I more detailed and holistic representation of work [6] $[7]$.

\section{Components of a Brahms Simulation}

Brahms has a multiagent language for describing agent and object activities. For a more detailed description of the language see [8] [4]. A Brahms simulation of work practice has seven integrated components:

Agent Model: The group-agent membership hierarchy of the people in the work system. Groups may be formal roles and functions or based on location, interpersonal relations, interests, etc.

Object Model: The class-hierarchy of all the domain objects and artifacts, e.g., tools, desks, documents, vehicles.

Geography Model: The geographical areas in which agents and objects are located, consisting of areadefinitions (user-defined types of areas, such as buildings, rooms, and habitats) and areas (instances of area-definitions).

Activity Model: The behavior of agents and objects in terms of the activities they perform over time [9]. Agent or object activities are mostly represented at the group-level or class-level respectively, but are also often specific to agents and objects. Activities are inherited and blended through a priority scheme.

Timing Model: Constraints on when the activities in the activity model can be performed, represented as preconditions of situation-action rules (called workframes). Activities take time, as determined by the predefined duration of primitive actions. Workframes can be interrupted and resumed, making the actual length of an activity situation dependent.

Knowledge Model: An agent's reasoning, represented as forward-chaining production rules (called (houghtframes). Thoughtframes can be represented at group/class levels and inherited. Thoughtframes take no rıme. Inquiry is modeled as a combination of activities 1:.g. detecting intormation, communicating, and reading/writing documents) and thoughtframes. Perception is modeled as conditions attached to

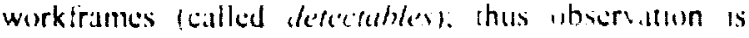
dependent on what the agent is derny

Communication Model: fotwons by which dyents and objects sxchange belicfs, inciuding telling someone something or asking a question. A conversarion is modeled as an activity with communication detions, either face-to-face or through some devies, such as a telephone or email. The choice of derice and how it is used are part of the work practics

Typically a Brahms model is ikerched by ipcilying the geography and groups first. The grain size of the simulation clock (time per tick) may vary from 5 seconds or less to 5 minutes or more. depending on the information available and modeling purposes. I model might represent a group of people as a single agent, a useful heuristic in redesigning a work system. Common objects and activities such as telephones and "phone conversation" may be easily reused and adapted from other Brahms models. In general, Brahms models represent work with much more detail than business process models, but somewhat less detail (and far more broadly) than cognitive models (Figure 1).

\begin{tabular}{|c|c|c|}
\hline $\begin{array}{c}\text { Cognitive } \\
\text { Model } \\
\text { (inference) }\end{array}$ & $\begin{array}{c}\text { Brahms } \\
\text { Model } \\
\text { (activitics) }\end{array}$ & $\begin{array}{l}\text { Business } \\
\text { Praiess } \\
\text { Mode! } \\
\text {, functions I }\end{array}$ \\
\hline
\end{tabular}

Figure 1. Relation of Brahms models to other models

Considerable effort is devoted to modeling objects (e.g., fax machines) and computer systems. with which people interact to accomplish their work.

\section{The Victoria Lunar Mission}

Victoria is the name of a proposed long-term semiautonomous robotic mission to the South Pole region of the Moon. The primary mission objecrive of Victoria is to verify the presence of water ice and other volatiles within permanently shadowed regions on the Moon. This will be accomplished by gathering the necessary lunar data for analyzing the history of water and other volatiles on the Moon, and by implication in the inner solar system. The Victoria team has decided to use a high-speed semi-autonomous rover.

One of the biggest constraints in any robotic mission is power consumption of the robot. In every acrivity the rover uses energy, therefore the sequence of sctivities for the rover is constrained by the amount of power available to complete the sequence. Whin the robot's batteries are low, it needs to rerum to a sun-exposed spor to recharge its batteries. During the Victoria mission the rover will traverse into permanently dark regions on the Moon. During these traverses the rover will use its neutron detector instrument to detcit hydrogen and the Sample Acquisition and Transter Blechanism (SATW) 


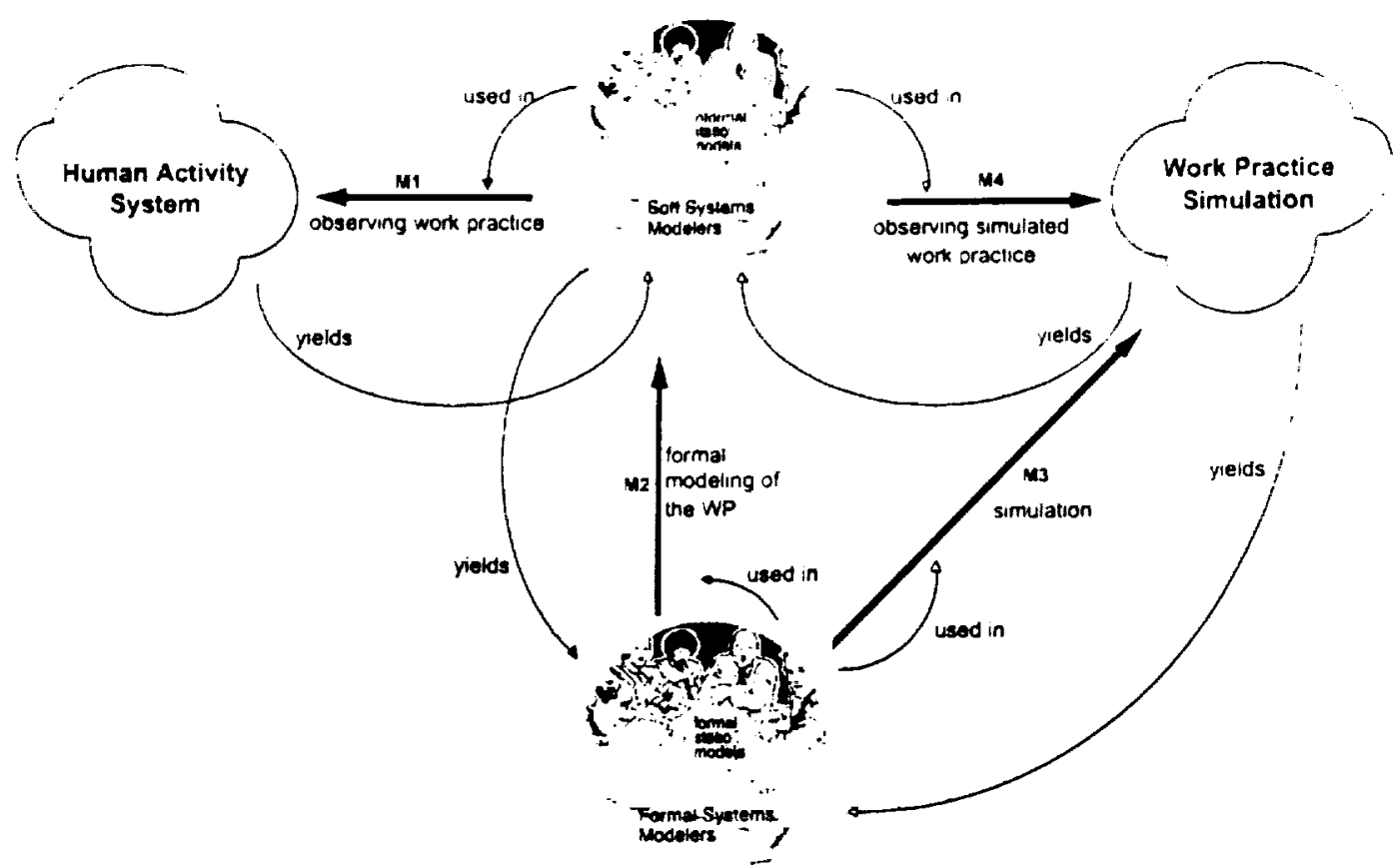

Figure 2. Collaborative Modeling Process

to drill into the lunar surface and take surface samples to be investigated using an array of science instruments.

The work system design problem is to configure the mission operations so the robot's activities inside the permanent dark region are most efficient (i.e. consume the least amount of energy)

\section{Collaborative Modeling}

To develop a simulation of the Victoria work system, we used a collaborative modeling approach with the Victoria mission designers. First, we created informal static models of the activities of the people, robot, and artifacts, the communication and geography, in informal design meetings and modeling sessions. Next, we translated these descriptions into formal Brahms models, producing simulation results (including energy measurements described below). The Brahms modeler went back to the mission design team and presented the result of the simulation. Together they discussed and represented more details of the work practice. The Brahms modeler implemented the new details into the simulation. This Brahms modeling-debug-simulate cycle continued until a sufficiently robust and interesting design resulted.

Figure 2 describes our collaborative methodology for developing first an informal model and then a formal simulation model of the Victoria work practice.

Method MI - analyzing work practice: The purpose of method MI is to create an informal static description (i.e. a conceptual model) of the work practice of a human activity system. For $\mathrm{Ml}$ we use the Compendium modeling method [10].

Method M2 - formal model of the work practice: The purpose of method M2 is to translate the conceprual models from $\mathrm{Ml}$ into a Brahms model. The Brahms modelers and the conceprual modelers do not necessarily have to be the same, and in fact, the skill sets for these two types of modelers are very different.

Method M3 - simulation: Using method M3 a Brahms simulation of the formal model is developed, by running the simulator with the formal model as input. M3 is the Brahms compile-simulate-debug method.

Method M4 - observing the simulation: The purpose of method M4 is to observe and investigate the work practice simulation output, and compare it with the actual human activity system. During this cycle the actual objective of the work practice simulation project is accomplished. Frequently, one modifies the model or factual scenarios (e.g., for Victoria, the location of ice in the modeled geography) to perform a what-if anaiysis

Thus, there is a modeling and simulation cycle between M1, M2, M3 and M4. The methods have to be closely integrated for the cycle to be efticient. Fur example, to a certain extent we can automatically produce Brahms model components (.M2) from :nformal Compendium descriptions (MI). 


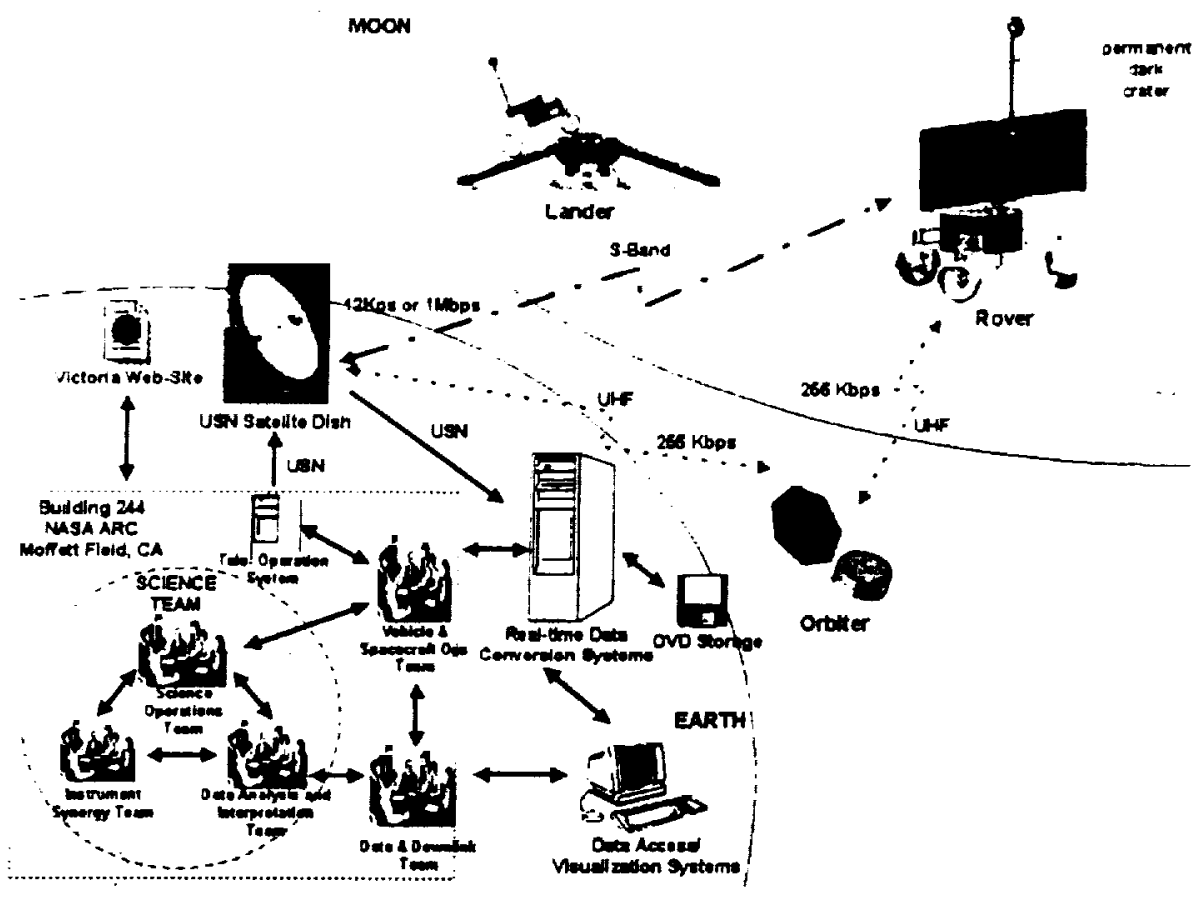

Figure 3. Victoria work system

\section{Mission Operations System Design}

The work during in the Victoria mission will be distributed over a number of human teams and the Victoria rover. By virtue of being people's arms and eyes on the Moon, the teleoperated rover is more of an assistant than a simple tool.

Figure 3 represents the work system elements and their relative location during the Victoria mission. The Science Team consists of co-located sub-teams: the Science Operations Team (SOT), the Instrument Synergy Team (IST), and the Data Analysis and Interpretation Team (DAIT). There are two other supporting teams: The Data and Downlink Team (DDT) and the Vehicle and Spacecraft Operations Team (VSOT). The teams communicate with the Victoria rover on the lunar surface using the Universal Space Network (USN), directly and via a lunar orbiter. The flow of data from the rover will be dominated by contextual data and science data. This data will come to NASA Ames via the Universal Space Network (USN) data connection and will be automatically converted in near real-time to accessible data formats that can be made available to the teams via data access and visualization applications.

Based on previous experience, the mission designers hypothesized that many issues will affect the decision cycle of the science team, one of which is data overload
[11]. They therefore specifically addressed the following questions in the work system design for Victoria:

1. How will science data be gathered collaboratively with the Earth-based science team, rover releoperator, and the rover on the lunar surface?

2. How will science data be made available to the science team?

3. What is the affect of a particular work system design on the power consumption of the rover during a science traverse into a permanent dark crater?

To answer these questions we developed a model of the activities of the teams, based on the description of a planned mission traverse. In the next sections we describe the design of this work system through the design of the agent model, the object mode!. their activity models, and the geographical model.

\subsection{Agent Model Design}

Figure 4 shows the group membership hierarchy on which the design of the work system is based. The agents in the model are the Earth-based human teams and the Victoria rover, as shown in Figure 3. The teams are represented as single agents, because at this mominr it is not possible to prescribe the compusition und practices of each team in more detail. For example, the "plan a command sequence" acrivity of the SOT represents the work of the whole ream, while the 

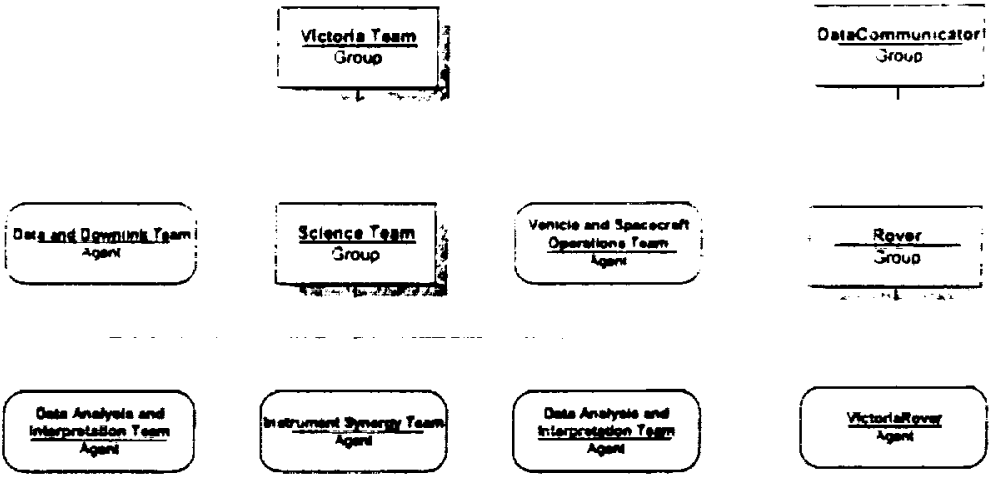

Figure 4. Victoria Agent Model

Table 1. Functional activity distribution over Victoria teams

\begin{tabular}{|c|c|c|c|c|c|c|}
\hline & $\begin{array}{l}\text { Seivence } \\
\text { Operalons } \\
\text { Toum }\end{array}$ & Simerentere & 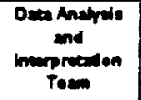 & $\begin{array}{c}\text { Deta and } \\
\text { Downthe Tous }\end{array}$ & 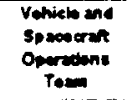 & Rerer \\
\hline $\begin{array}{l}\text { Uphink } \\
\text { processs }\end{array}$ & 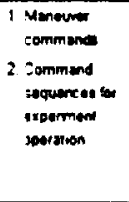 & 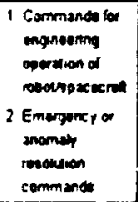 & 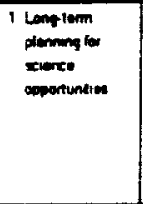 & 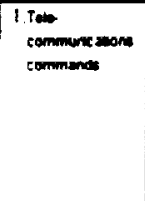 & 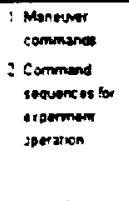 & $\begin{array}{l}\text { Cammend } \\
\text { ircison }\end{array}$ \\
\hline $\begin{array}{l}\text { Downilink } \\
\text { process: }\end{array}$ & & 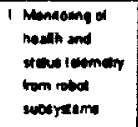 & 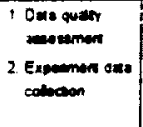 & 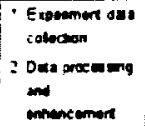 & & 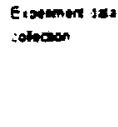 \\
\hline
\end{tabular}

individual activities of each team member remain unspecified. The Victoria rover is modeled as an agent because it has activities, including primitive actions that change the world, movements, and communications.

Table I shows a possible distribution of the functions over the Victoria teams [12]. Details of how different teams collaborate to perform these functions constitute the work practice, as specified in the situation-action rules (Brahms workframes) of the different agents.

An example workframe for the SOT team for creating a command sequence for finding water ice is (paraphrased): When I believe that there is a possibility we can find water ice at the current location of the rover, then start the activity of finding water ice. Generically, a workframe is of the form: When (I believe $\left.\{X\}^{*}\right)$ Do \{activity $A$, conclude a new belief and/or fact * $^{*}$

\subsection{Object Model Design}

The object model consists of the classes and instances of physical artifacts, as well the statically and dynamically created data objects during the simulation. The Victoria object model (Figure 5) includes classes for the science instruments on the rover and other objects contained in the rover, such as the carousel and the battery. Furthermore, the model includes the data communicator class, which includes the objects for $S$. band and UHF communication. The model also includes the software systems that receive and convert the mission data. A Brahms object represents the data visualization systems that present data to the Victoria team. The Data and CoreSample classes allow dynamically treating objects representing specific dut.t and lunar core samples during the simularion.

\subsection{Geography Model Design}

The geography model represents locations on Earth and the Moon (Figure 6). The areas of interest on Earth are Building244. where the Victoria teams and systems are located. and UsnSatelliteLucition. where the 


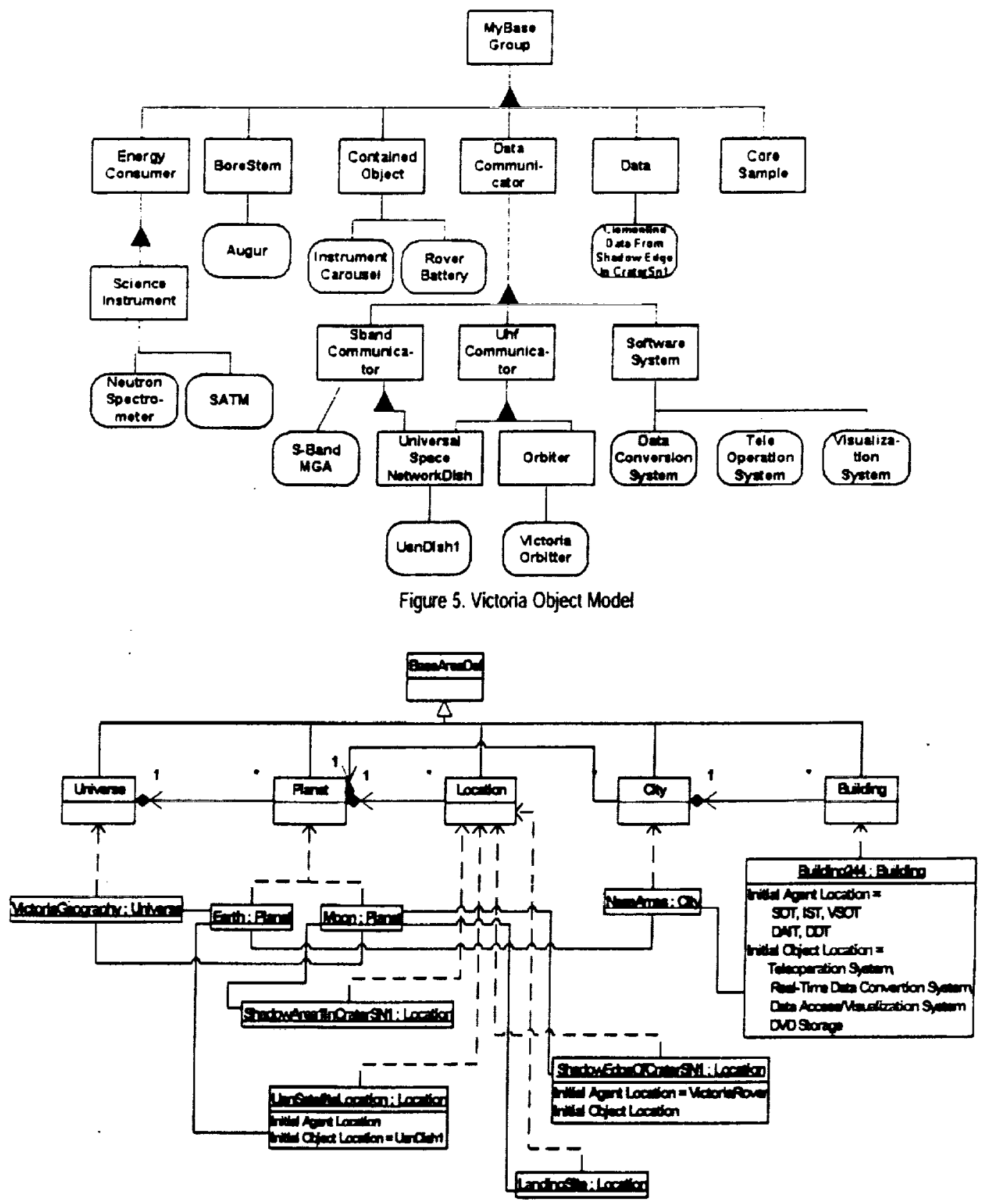

Figure 6. Victoria Geography Model

LisnDishl satellite dish is located. Locations for the simulated scenario are represented on the Moon

ShadowEdgeOtCraterSN 1 represents the location the rover at the start of the simulation (the shadow edge in crater SNI). ShadowAreallnCraterSNI represents the area in the permanent shadowed SNI crater where the rover will perform a drilling activity. The LandingSite area is represented only for completeness.

\section{Victoria Simulation Scenario}

The case study selects one of the key surface activities, searching for water in permanently shadowed craters:

The rover has arrived at the shudow edge of crater site number 1 . The batsen has heen filly charged. Based on the data analvis: by the Earth-hased teams. "l 


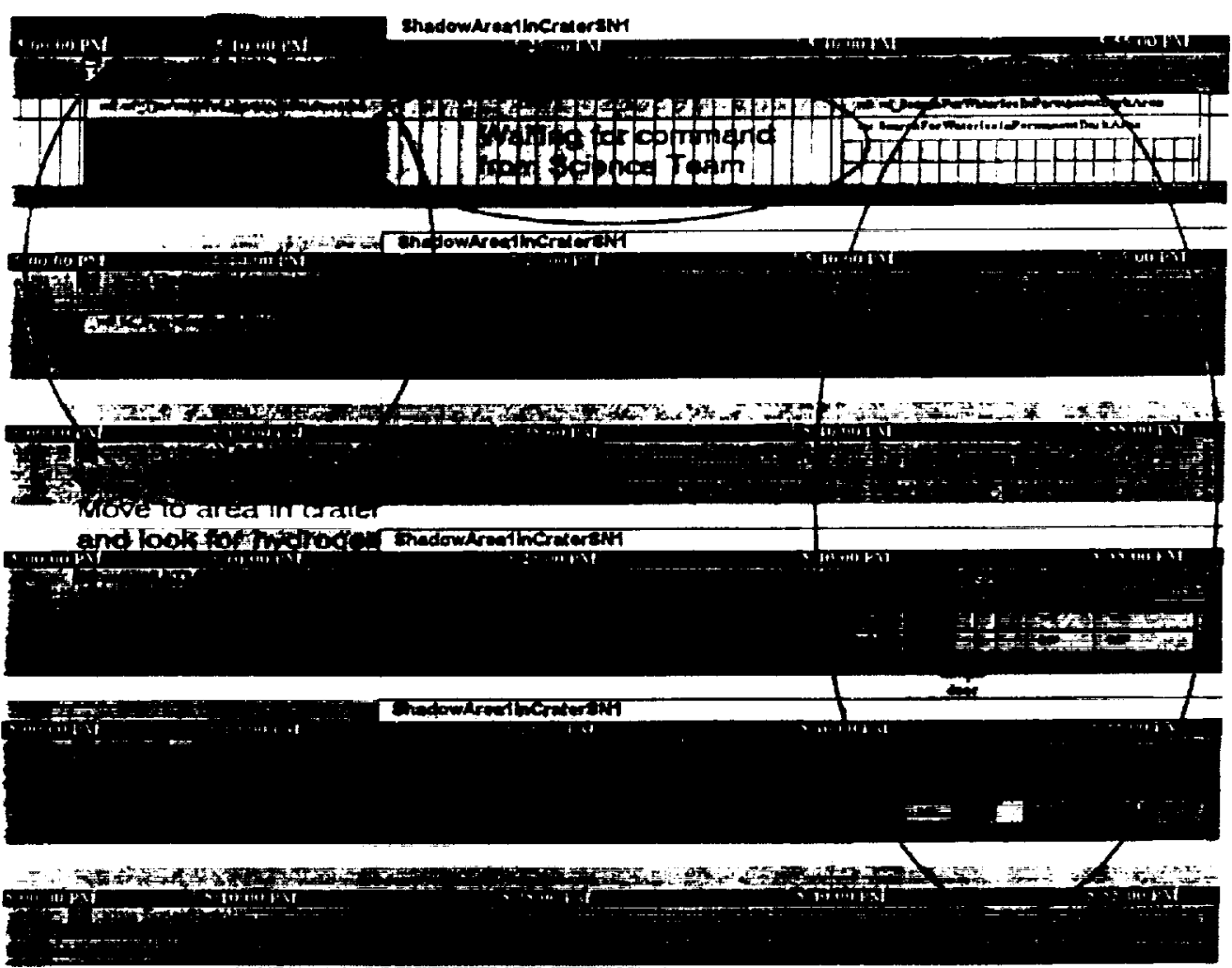

Figure 7. Victoria Rover scenario activities

the Clementine data available for the shadow edge area of crater site number 1 , the science team now decides where to go into this crater and search for water ice. While the rover is traversing into the crater, it is taking hvdrogen measurements with the Neutron Spectrometer. When the rover arrives at the assigned location within this crater and it finds hydrogen there, the science team decides it should sturt drilling $10 \mathrm{~cm}$ into the surface using the S.ATM. and collect a l.Occ lunar sample. When the rover receives this command, it starts the drilling activity and finally deposits the sample into the instrument carousel.

The rover uses two instruments in this scenario: the Neutron Spectrometer (to detect hydrogen-most likely caused by water ice-within the first half meter of the lunar surface below the rover) and the lunar surface drill (Sample Acquisition and Transfer Mechanism SATM)

The backbone of the simulation model consists of three primary activities: Data uplink, Rover operations, and Uplink. These are described in the next section.

\section{Simulation Results}

The simulation provides visibility into the behavior of the work system uver time, that is, detivitiss. communication, and movement of each agent and object. After the model is developed and compiled, the Brahms simulation engine executes the model. A relational database is created, including every simulation event. An end-user display tool called the AgentViewer uses this database to display all groups. classes, agents, objects, and areas in a selectable tree view. The end-user can select the agents and objects he she wants to investigate. The AgentViewer displays an ucrivity time line of the agents and objects selected, optionally showing agent and object communications. Using this view the enduser can investigate what happened during the simulation. In the next three sections we explain the key behaviors during the simulation.

\subsection{Data Uplink Activities}

The scenario starts with the Data Analysis and Interpretation Team (DAIT) retrieving the Clementine data image of the shadow edge srea. where the rover is located at the start of the scenario. They review this image using their visualization system, represented in the Brahms model as a VisualizationSystem object. According to the work practics, they do this without anyone requesting that they look it the data. 


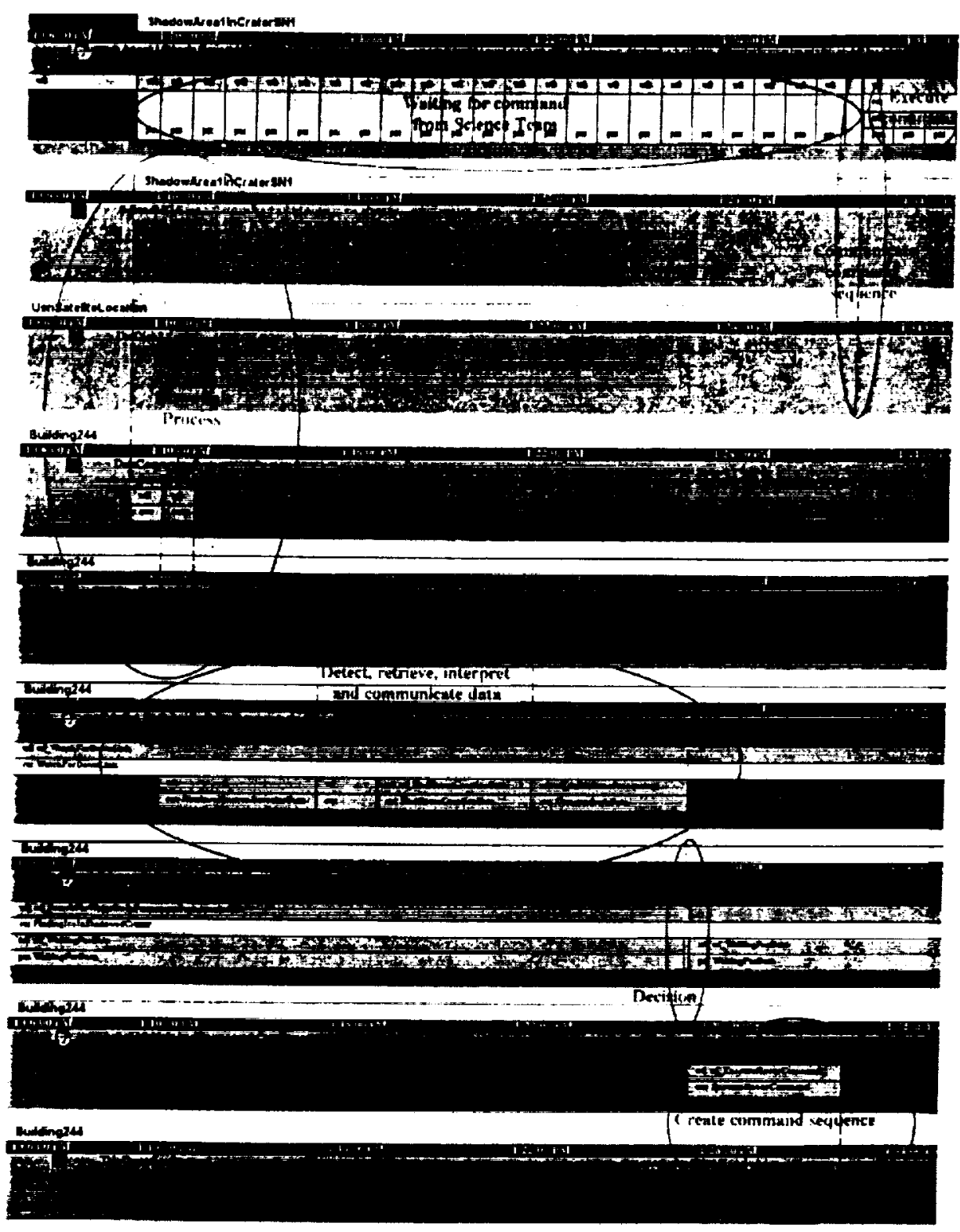

Figure 8. Simulation of downlink and second uplink command activities

This means that the DAIT needs to be know: 1) the location and sifuation of the rover at all times. 2) whether data is available and needs to be retriesed, and 3) where and how they ian retrieve data.

Once the DAIT has retrieved the images, it communicates this to the Science Operations Team (SOT), and they collaboratively analyze these images (the AnalyzeRoverlmages activity). When donc, the SOT plans the rirst rover command sequence. Aciording to the scenartu being simulated, the SOT decides that the rover necels 4 drive lor a specitied anount of tume 115 min) into the crater to a specific location (ShadowAreallnCraterSNI), and while driving it should be using its neutron detector instrument to detcet hydrogen in the lunar surtace. This decision is communicated to the Vehicle and Spacecratt Operations Team (VSOT), as well as to the DAIT After this communicarion. the SOT waits for the rovir's downlink Jata.

\subsection{Rover tctivity}

The Vkeuru ruber is mudeled as an agene, whereds 
the ncurron spectrometer and SATM instruments are modeled as separate science instrument objects contusned in the rover agent. In the scenario model. the veurron Spectrometer object is active and creates a llydrogenData_l ubject containing the hydrogen data that is vent to Earth while the VictoriaRover is traversing to a permanently shadowed area within the crater SNI The rover then waits for the next command sequence from Earth. During this time the teams on Earth are analyzing the hydrogen data and deciding what to do next. In the Uplink activity, the rover is given the command to search for water ice in the permanent dark area. This triggers a traverse, during which the SATM instrument will start the drilling activity.

To collect a sample the SATM has to 1) lower its augur to the surface, 2) drill to the depth given as part of the command by the SOT (in this scenario the command says to take a $1.0 \mathrm{cc}$ sample at $10 \mathrm{~cm}$ depth), 3) open the sample cavity door, 4) continue to drill to collect the sample, 5) close the sample door when done, 6) retract the drill from the surface, and 7) deposit the collected sample on the instrument carousel. (see "Drill $10 \mathrm{~cm}$ into surface and take lcc sample" in Figure 7).

In the Brahms model, the Augur object creates the LunarSample_l object as part of its activity to capture the lunar sample, after opening the sample door and continuing the drilling to collect the $1.0 \mathrm{cc}$ sample. The activity times for drilling into the surface are dynamically derived during the simulation.

\subsection{Downlink Activity}

When the rover detects hydrogen in ShadowArea InCraterSN1 the downlink process starts (represented by the Brahms AgentViewer in Figure 8). The VictoriaRover agent contains the S-BandMGA object, which represents the S-Band transmitter on the rover. The VictoriaRover creates a data object with a) the current rover location information and b) the hydrogen data. This data object is then communicated to Earth, via the UsnDishl object. The UsnDishl object communicates this data to the DataConversionSystem, located at NASA Ames.

As can be seen in Figure 8 (see "Downlink process"), the DataConversionSystem performs two conversion activities, one for the hydrogen data and one for the location data from the rover. The work system design requires that the data conversion system interact with the visualization system without human intervention.

When the VisualizationSystem receives the newly converted data, the system alerts the DAIT. A member of the DAIT monitors the VisualizationSystem while in the activity WatchForDownlink (see "Detect, retrieve. interpret and communicate data" in Figure 8). When the DAIT agent detects that there is newly dvailable neutron detector and location data, it retrieves the datal firm the Visualizationsystem object the atturtics RutrieveNeutronData. InterpretveutronData, and FindRoverLucation Data).

Next, the DAIT communicates their findings to the SOT In the example iecnario. the data sugecst that the rover has tound hydrogen in Shadow. Area! InCraterSn I Given this finding, the SOT quickly determınes the next command sequence for the rover and communicates this decision to the VSOT isee "Nexr Ruicr Cummand Decision" in Figure 8 ).

The communication informs the VSOT to transmit the command sequence to the Victur:sRover lise "Create command sequence" in Figure 3 ). The command sequence tells the VictoriaRover to start the SearchForWatericelnPermanentDark. Area activity. It also tells the VictoriaRover that its sub-activity is to perform the DrillingActivity. Parameters indicate how deep to drill and how big a sample to collect at that depth. Figure 8 shows part of this second uplink process.

The duration of the downlink and second uplink processes determine the duration of the second DoNothing activity of the VictoriaRover, simulating the time the rover is waiting for the Victoria science team to decide the next command sequence (see "Waiting for Command from Science Team" in Figure 3 ).

\subsection{Modeling Energy Consumption of Rover}

To calculate the total energy used by the rover. we need to represent in the model the energy needed for each subsystem during a rover activity (see equation (1)). The total power consumption of the rover during the scenario can then be calculated (equation (2)).

$$
\begin{aligned}
& \text { Total Power Consumption }=\sum_{i=0}^{n} E_{a s n} \text {. }
\end{aligned}
$$

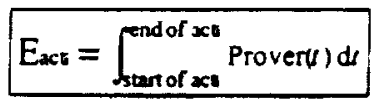

The energy consumption for every rover activity during the simulation of the scenario is shown in Figure 9. In particular, the energy the rover uses during the Waiting activity (see "waiting for command from science team" in Figure 8 ) is defined by the energy" needed for Thermal Protection during driving Command and Data Handling during driving. While the rover is standing still and "doing nothing." it consumes power for its thermal protection and its commanding and data handling for its subsystems, such is its processor board.

Besides the power left to use after the scenario. another interesting variable is the energy usige rate by the rover lequation ( 3 ) 
fincreykale = Tolal Power Phallerylvart of enaverse)

This equation shows that given the energy used in the secnario -drive $900 \mathrm{~m}$ into the crater, and take one $1.0 \mathrm{cc}$ iampli at $10 \mathrm{~cm}$ Jepth-with the eurrent work system Jesign, the robot has used almust a third of its power:

Energy Ruteidrilling in permunent dark (ruter) $=0.30$

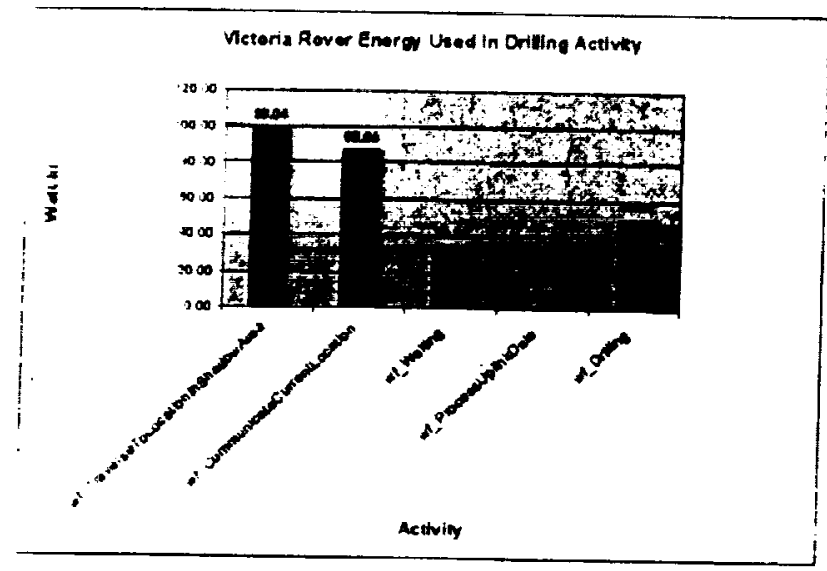

Figure 9. Rover energy used in high-tevel activities from simulation hislory database

This variable represents the rover power consumption, a measure of the effectiveness of the work system design. which can be used to compare different work configurations for the modeled scenario.

\section{Conclusions}

In this paper we described how Brahms was used to design the mission operations work system for the Victoria mission.

The Brahms simulation showed the impact of the work practice of Earth-based teams on activities and energy consumption of the rover. The simulation allows mission designers to compare different work system designs before critical mission decisions have been implemented.

We have shown an instance of a collaborative work system design methodology incorporating simulation. The Brahms simulation framework provided guidance to mission and robot designers, replacing a spreadsheet approach by a more transparent and flexible multiagent representation.

\section{References}

[1] T. H. Davenport, Process Innovation: Reengineering Work through Information Technolugl: Boston. MA: Harvard Business School Press, 1993.
[2] F E Einery and t: L. Trise. "Sociu-Tohnucal Systems." in Hanagement Sipencis. Woteds und Technicutes, $C$ W. Churchmin, lid. Lundon: Pergamon. 1960.

[3] J. Greenbaum and $W$. Kyng. "Design at Wurk Cooperative design of computer systems." Hillsdale. NJ.: Lawrence Erlbaum. [wo]

[4] M. Sierhuis, "Modeling and Simulating Work Practice: Brahms A multiagent modeling und simulation language tor work sysicin snalysis and desing," in Socral Science and Informaricy $(S W I)$. Amsterdam. The Vetherlands: University of Amsterdam, SIKS Disstrtation Series No. 2001-10, 2001, pp. 350.

[5] M. Sierhuis, W. J. Clancey, R. v. Hoof, and R. d. Hoog, "Modeling and Simulating Human Activity," presented at AAAI Fall Symposium on Simulating Human Agents, North Falmouth, MA, 2000.

[6] W. J. Clancey, P. Sachs, M. Sierhuis, and R. van Hoof, "Brahms: Simulating practice tor work systems design," International Journal on Human-Computer Studies, vol. 49, pp. 831865,1998

[7] M. Sierhuis and W. J. Clancey, "Knowledge. Practice, Activities, and People," .t.t.t/ Spring Symposium, B. Gaines, Ed. Stanford University, CA.: Proceedings of AAAI Spring Symposium on Arrificial Intelligence in Knowledge Management, 1997, pp. 1+2-148.

R. van Hoof and .Y. Sierhuis. "Brahms Language Reference," NASA Ames Research Center, 2000.

[9] W. Clancey, J., Situated Cognition. On Human Knowledge and Computer Representations: Cambridge University Press, 1997.

[10] A. Selvin, S. B. Shum, M. Sierhuis, J. Conklin. B. Zimmermann, C. Palus, W. Drath, D. Horth, J. Domingue, E. Motta, and G. Li. "Compendium: Making Meetings into Knowledge Events," presented at Knowledge Technologies 2001, Austin, TX, 2001

[11] G. Thomas, M. Reagan, E. A. Bettis III, N. Cabrol, and A. Rathe. "Analysis of science. team activities during the 1999 Marsokhod rover field experiment: Implicultons for automated planerary surtace exploration." The University of lowa. lowa City 1909.

[12] S. D. Wall and K. W. Ledbetter, Design of Mission Operctions Sistems lisr Scientific Remote Sensing. Lundon: Taylot \& Francis. 1991 